O mais interessante é o fato de que essa incorporação do princípio da autonomia se deu de fora para dentro, ou seja, a partir da codificação internacional o princípio entrou no ordenamento jurídico interno de diversos países.

Assim, o princípio da autonomia da vontade como norma de conexão aplicável aos contratos internacionais é considerado nos dias de hoje como regra universal. Adotado em alguns países através de complexas construções doutrinárias e jurisprudenciais, o princípio foi ganhando força em foros internacionais e nos últimos anos foi incorporado ao sistema jurídico de vários países, como norma cogente, através de convenções internacionais.

No Brasil a situação ainda não evo luiu, na esteira do desenvolvimento do prin cípio no plano internacional. A LICC, no seu art. 9, não menciona o princípio. Em bora muitos juristas sejam a favor, entendemos que, em verdade, o princípio aqui está proibido. Esta afirmação decorre da leitura do art. $9^{\circ}$ que não pode ser comparado com outras normas sobre o tema que o permitem expressamente, como por exemplo na Convenção sobre lei aplicável aos contratos internacionais, verbis:

vel

“Determinação do direito aplicá-

\section{Art. $7^{\circ}$}

O contrato rege-se pelo direito escolhido pelas partes. $O$ acordo das partes sobre esta escolha deve ser expresso ou, em caso de inexistência de acordo expresso, depreender-se de forma eviden- te da conduta das partes e das cláusulas contratuais, consideradas em seu conjunto. Essa escolha poderá referir-se à totalidade do contrato ou a uma parte do mesmo.

A eleição de determinado foro pelas partes não implica necessariamente a escolha do direito aplicável."

E a jurisprudência tampouco esclareceu a matéria, como se vê da análise dos poucos casos existentes. Nos casos pesquisados, notamos que os juízes usaram o método conflitual para determinar a le aplicável, sempre encontrando como resultado a lei brasileira ou a lei estrangeira, a partir de uma interpretação literal do art. 9, caput.

Por isso, apesar de sermos favoráveis à autonomia, especialmente em face do aumento dos contratos internacionais decorrentes do incremento comercial em razão dos processos de globalização e integração regional, concluímos que a legislação vigente não contém nenhuma norma indicativa da sua aceitação.

Assim, somente através da substituição do art. 9ํ da LICC por normas que expressamente permitam a autonomia da vontade teremos uma modificação da situação atual. Finalizando, sugerimos que o Brasil adote a Convenção Interamericana sobre o direito aplicável aos contratos internacionais, não só para regular os contratos internacionais entre os parceiros latino-americanos mas também como regra conflitual à todas as relações contratuais internacionais, substituindo, afinal o inadequado art. 9ㅇ da LICC.

\title{
Mercosur - Una Introduction
}

\author{
Ricasdo Luis Loxenretti
}

Professor de la Universidad de Buenos Aires

\section{Descripcion Del Sistema Juridico Del Mercosur}

\section{Introducción: los vicios} del jurista

a actitud de los juristas frente a Mercosur es un verdadero desafio, $y$ encierra algunos vicios.

Por un lado,estàn quienes aceptan la marginaciòn, ya que es un tema de los economistas, quienes se ocupan de las cosas verdaderamente importantes.- Ello es hoy insostenible, ya que ha quedado demostrado que la apertura indiscriminada de campos desregulados provoca efectos distorsivos que afectan la eficiencia econòmica y desertifican la sociedad humana.-

Una vez decididos a participar, los juristas solemos ser perezosos : todo lo que hace falta es imitar lo que se ha hecho en europa.- De este modo, el Mercosur serìa una suerte de "uniòn europea en desarrollo", con lo cual no se hace màs que reeditar los vicios imitativos y la cultura de la traducciòn, que tanto daño hicieran en los àmbitos nacionales.
La cultura jurìdica occidental suele ser dividida en anglosajona y continental europea, y pareciera que las discusiones no tienen cabida.- Sin desconocer las virtudes, olvidamos los desastres producidos por ambas culturas jurìdicas que han dibujado un final de siglo del cual no pueden enorgullecerse demasiado.- Imitar lo bueno,pero ensayar una cultura jurìdica latinoamericana, o mercosuriana es una buena tarea : la protecciòn ambiental, del consumidor, la igualdad, el pluralismo, el eclecticismo, son caracterìsticas que debemos recuperar para el diseño de una sociedad jurìdicamente organizada.-

En el plano formal se ha utilizado la palabra "Código" para mencionar el sistema jurídico del 'Mercosur.- Evidentemente, si se identifica al Código con una regla estatal ordenada racionalmente que establece la existencia de axiomas que son aplicables al caso concreto mediante un juicio deductivo, no puede decirse que esa sea la situación en el Mercosur.-

Ello no significa inhibir su utilización para expresar otros sentidos.- En un primer 
aspecto, refiriendose al origen, la idea de Código ha sido identificada como norma sistemática emanada el Estado; en el futuro puede serlo de la Comunidad. - En otro aspecto, metodológico, el Código es un sistema cerrado, que difícilmente pueda ser usado en una comunidad de Estados e individuos interactuando dinámicamente. También puede aludirse al Código como un subsistema, como ocurre con la expresión "Código de los Contratos", o "Código de consumidor", refiriendose a un sistema de normas axiomáticamente cerrado aplicable a un sector especifico de las relaciones jurídicas.-

En otro sentido, puede pensarse en la noción de Código como elaboración dogmática de la doctrina que va identificando los axiomas fundantes de un sistema abierto con pluralidad de fuentes $y$ de normas.-

Esta es la única tarea posible, y la mas fértil, que puede realizar la doctrina jurídica al examinar un cuerpo jurídico como el emergente del Mercosur.

La tarea del jurista es bucear en las fuentes jurídicas del derecho del Mercosur: el tratado de Asunción, los subsiguientes, las Constituciones de los Estados Partes, los otros Tratados que no se refieren a la integración que los vinculan, la Costumbre y todo el derecho derivado, para encontrar allí las normas jurídicas vinculantes.-

Enseña Cueto Rua ${ }^{1}$ que "las fuentes del derecho son los criterios de objetividad

a los que acuden los órganos comunitarios para la decisión de los conflictos o los integrantes del grupo social en la elección de cursos de conducta que por su objetividad faciliten el entendimiento colectivo".- Las fuentes son criterios a los que se recurre en el proceso de creación normativa en búsqueda de objetividad.-

Por ello, y para ayudar al operador jurídico, la doctrina debe trabajar identificando las normas generales y las reglas aplicables a casos concretos; hay que realizar una dogmática sistemática.-

\section{Normas originarias,}

\section{fundamentales y derivadas:}

Examinadas las fuentes y constatada la ausencia de un derecho tipicamente comunitario, verificamos distintos tipos de normas.- En cuanto al origen, se distingue entre el derecho originario y el derivado, conforme ya lo explicamos.- En el ámbito del Mercosur, este ultimo esta constituido por decisiones, resoluciones, directivas, que veremos mas adelante.-

En cuando al orden jerárquico corresponde discernir entre aquellas normas fundamentales y las derivadas. - Las primeras son las que por recepción en una fuente originaria y por el carácter de principios fundantes, no pueden ser alteradas y condicionan a las normas de carácter inferior $^{2}$. Se les adjudica un carácter fundante de la actividad legislativa puesto que son una suerte de pensamientos directores de

1. CUETO RUA, Julio, "Fuentes del derecho", Abeledo Perrot, Bs.As, reimpr.1982, pág.24

2. para ampliar nos remitimos a ntro libro "Las normas fundamentales de Derecho Privado", Ed. Rubinzal y Culzoni, 1995

Revista da Faculdade de Direito da UFRGS, v. 17, 1999 una regulación posible ${ }^{3}$ - También controlan el excesivo activismo judicial, confiriendole un contexto normativo de actuación ${ }^{4}$.

Constituyen un tipo de normas férreas, inderogables, un cerco limitativo para la actividad legisferante, judicial, y para la circulación de bienes y servicios en el ámbito de la integración.-

En las fuentes del Mercosur encontramos una pletora de objetivos, principios, valores, que cumplen esta función.Consecuentemente distinguiremos entre normas fundamentales y las derivadas. Entre las primeras se encuentran los principios, reglas y valores que apreciaremos seguidamente.-

\section{Principios y reglas}

Es importante aclarar que tanto los principios como las reglas se refieren al ámbito del deber ser, y por lo tanto son normas; son enunciados deontológicos.- Se trata entonces de distinguir entre dos tipos de normas, siendo los criterios más aceptados los siguientes:

El primero es el de la generalidad: los principios tienen una generalidad mayor que las reglas. - Una ley, es general respecto de los supuestos de hecho que contempla, puesto que no puede referirse a un sólo caso.- Los principios, en cambio, son generales también respecto de las reglas.-

Desde este punto de vista, la diferencia entre uno y otro es de grados y no esencial.-
El segundo es el origen: las reglas son creadas, los principios desarrollados. - Estos últimos no se basan en la decisión de ningún legislador o tribunal, sino en un sentido de conveniencia u oportunidad que se desarrolla históricamente.- Tampoco tiene sentido el rechazo o la derogación de un principio, ya que ellos permanecen y se actualizan constantemente.- La tarea del jurista es de descubrimiento.-

El tercero es la referencia a la idea de derecho: presente y explícita en los principios; presente e implícita en las reglas.-

Este es un elemento importante puesto que el principio, al referirse explícitamente a la "idea" de derecho, ordena algo para ser realizado en la mayor medida posible, dentro de las posibilidades jurídicas existentes; son mandatos de optimización ${ }^{5}$.-

Las reglas, en cambio, pueden ser cumplidas o no; si es válida debe cumplírsela.-

Por ello, la colisión entre normas produce el efecto de excluir una, porque el resultado de aplicar las dos es incompatible.La colisión de reglas se desenvuelve en el plano de la validez.-

En cambio, en los principios, hay una cuestión de precedencia y no de desplazamiento.- Se dice que tienen diferente peso en el caso concreto; la aplicación de uno no invalida al otro.-

3. LARENZ, Karl, "Derecho justo. Fundamentos de ética jurídica", Civitas, 1985, pág. 32.

4. LASARTE, Carlos, "Principios de derecho civil", Trivium, Madrid, 1992, T,1, 79 y 80 .-

5. ALEXY, Robert, "Teoría de los derechos fundamentales", Centro de Estudios constitucionales, Madrid, 1993, pág. 86.- 
Con referencia a este último aspecto, decía Betti ${ }^{6}$ que los principios tienen una excedencia de contenido deontológico en relación a las normas; siempre se refieren a un "óptimo".-

\section{Valores y principios:}

Los valores son por sí mismos distintos, porque son conceptos axiológicos, no contienen un mandato o una prohibición, sino una valoración.-

La valoración puede ser de tipo comparativo cuando de dos objetos se dice que uno tiene mayor valor que otro, expresandose juicios de preferencia o equivalencia.- En otros casos pueden ser clasificatorios, que sirven para la categorización de objetos, y métricos, cuando a lo que hay que valorar se le atribuye una medida, como ocurre en las obligaciones de valor.-

En nuestro caso hablamos de valoraciones comparativas.- El modo de interpretar el valor es entonces mediante un juicio comparativo, que denominaremos juicio de ponderación, ya que se trata de establecer una medida, un equilibrio.-

Los valores que motivan nuestro interés son los "intrasistemáticos", es decir, aquellos que tienen existencia dentro del ordenamiento mediante una regla de reconocimiento.- Son también normas, y al igual que los principios, se refieren explícitamente a la idea de derecho.-

\section{La función normativa de los} principios y valores en el derecho de la integración

No hay tratado que no incluya un catalogo de principios y valores; se tiende a legislar por principios y no por supuestos de hecho?.- ¿Por que razón?, ¿cual es su utilidad?.-

La explicación de su surgimiento es sencilla.- Ante el evidente desprestigio de la ley producido por la superproducción legislativa, ante el peso abrumador que tienen los digestos y las oscilaciones de la ordenamientos que conviven en el contexto de la globalización del mundo, se postula cada vez más una tarea de simplificación en base a principios.-

En su larga historia, estos han mostrado dos virtudes que les han dado fortaleza.- La primera es su simplicidad, o por lo menos la aspiración de tener un conjunto de ideas que guían el cálculo jurídico.- La segunda es su jerarquía superior puesto que cualquiera sea la concepción que se desarrolle acerca de ellos, siempre se los el derecho natural, para otros tienen una raíz histórica; para otra opinión son interiores al ordenamiento, pero se obtienen por generalización de normas y son superiores a ellas.- Esta altura, esta superioridad es la que permite conferirles una función de control, de límite, de guía de la actividad infraprincipial. jurisprudencia, ante la multiplicidad de ha ubicado bien alto: para algunos integran

6. BETTI, Emilio, "Interpretación de la ley y de los actos jurídicos", Edersa, Madrid, 1975,pág. 287

7. RODOTA, Stefano, "Ideologie e tecniche della riforma del diritto civile, Riv dir commerciale, 1967,I, pág. 86)

Revista da Faculdade de Direito da UFRGS, v. 17, 1999
Con estos caracteres de simplicidad y de alta jerarquía, los principios constituyen una "armazón", una "arquitectura" del ordenamiento jurídico.- Este fenómeno ha hecho que se aluda a una concepción "principial" del derecho ${ }^{8}$, y que se hable indiferenciadamente de principios, valores y derechos fundamentales.-

Con excepción de lo expuesto en los puntos anteriores, excede nuestros propósitos el distinguir exhaustivamente entre todos estos tipos de normas.- Solo nos interesa rescatarlos del olvido en que han quedado.-

\section{A) Las normas "prima facie"}

La doctrina actual es coincidente en que los principios son normas ${ }^{9}$.

Los principios, como su propio nombre lo indica, se oponen a algo acabado, terminado, son ideas germinales ${ }^{10}$.-

Son normas "prima facie" sin una terminación acabada, y por lo tanto flexibles, susceptibles de ser completados.Para Alexy ${ }^{11}$ los principios son mandatos de optimización, puesto que ordenan que se realice algo en la mejor medida posible, pueden ser cumplidos en diversos grados.-

Es decir que los principios son normas, pero de un tipo especial.- Tienen una estructura deontológica puesto que señalan un deber ser, pero son distintos que las reglas porque éstas pueden ser cumplidas o incumplidas de un modo claro.- El principio en cambio, ordena que algo sea cumplido en la mejor medida posible; es una búsqueda de lo óptimo.-

Los principios son normas que receptan valores y como tales no pueden ser sino aspiraciones cuyo grado de concreción varía según los sistemas jurídicos, los períodos históricos, y la relación con las reglas.-

\section{B) La relación jerárquica y el uicio de ponderación} estructura deontológica definida como mandato de optimización lleva a la necesaria consecuencia de que necesitan de otros elementos para tener una idea concreta y terminada de lo que en definitiva significa un principio en un sistema jurídico concreto y en un caso.-

Este no puede ser aplicado directamente como una regla jurídica.- El principio no expresa una idea objetiva, certera, que impulse al juez a un juicio silogístico; no se lo puede considerar como una premisa mayor y subsumir en él a un caso.-

En este sentido, el principio es excesivo, expresa demasiado porque es una aspiración; como dice Betti ${ }^{12}$, son criterios
Este contenido inacabado y su

8. DE LOS MOZOS, Jose Luis, "Metodología y ciencia en el derecho privado moderno", Edersa, 1977, pág. 104

9. BOBBIO, Norberto, "Teoría general del derecho", Temis, Bogotá 1987, pág. 239; VIGO, "Los principios generales del Derecho", JA. $1986-111-860$

10. BETTI, Emilio, "Interpretación de la ley y de los actos juridicos", Rev. Der. Privado,Edersa, Madrid, 1975, pág 283

11. ALEXY, Robert, "Sistema jurídico, principios jurídicos y razón práctica", Doxa, Año 1988, Num. 5 pág. 143

12. op cit, pág 287) 
de valoración que se caracterizan por una excedencia de contenido deontológico; por ello hay que medirlo, establecer su relación con otros principios y reglas para llegar a un contenido.-

Este contenido se establece mediante un juicio de ponderación con otros principios.- Ponderar es establecer comparaciones, establecer el peso de cada uno y aplicar el mayor en el caso concreto.Por eso, el grado de generalidad no es decisivo para el principio jurídico; lo importante es su aptitud como causa de justificación ${ }^{13}$.- Por ello es necesario identificar principios que son contradictorios, complementarios y otros competitivos entre si.-

\section{C) La función integrativa, interpretativa, finalística y delimitativa:}

Hay una larga tradición jurídica afirmada en la irrelevancia normativa de los principios y valores.- Su abstracción impediría asignarles toda función puesto que su diseño deontológico no lo permite. Esta tesis ha llevado a que el legislador, sobre todo el de los tratados internacionales haya utilizado indiscriminadamente los valores y principios, con la tranquilidad de que los firmantes no resultan obligados por ellos. Surge así un derecho cuya liviandad es insostenible frente a un ciudadano expectante.-

Por ello la doctrina postula algunos cambios $^{14}$. Algunos autores afirman que ya

\section{Larenz, pág. 36)}

14. hemos insistido en ello en nuestro libro "Las normas fundamentales de Derecho Privado"

15. conf CAPPELLETI, Mauro, "Is the European Court of Justice running wild?, ELR, vol 12, num 1, febrero de 1987, pags 8.9)

es una tendencia consolidada en Europa y Estados Unidos la que considera que las disposiciones existentes en los preámbulos o los valores y objetivos, son vinculantes en punto a obligar al Estado a no transgredirlos o a implementarlos ${ }^{15}$.-

Desde nuestro punto de vista, es posible adjudicarles las siguientes funciones:

- función integrativa: es un instrumento técnico para colmar una laguna del ordenamiento.-

- función interpretativa: es un modo de subsumir el caso en un enunciado amplio.- Ayuda al interprete a orientarse en la interpretación correcta, adecuándola a los valores fundamentales.-

- función finalística: permite orientar la interpretación hacia fines más amplios, de política legislativa.

- función delimitativa: pone un limite al actuar de la competencia legislativa, judicial y negocial.- Sin que se ahogue la tarea creativa y dinámica del derecho, los principios jurídicos constituyen lineamientos básicos que permiten establecer un límite, al igual que los valores, a las bruscas oscilaciones de las reglas.-

- función fundante: ofrece un valor para fundar internamente al ordenamiento, y dar lugar a creaciones pretorianas.-

Además se ha señalado que existen pretensiones de operatividad, tema cuya complejidad excede nuestra labor en este texto.-

\section{Su existencia en el Derecho del Mercosur}

Se ha objetado que ni el Tratado de Asunción, ni los Protocolos de Brasilia y Ouro Preto, refieren de manera expresa a los principios generales como fuente del Derecho comunitario, lo que sumado a la ausencia de un Tribunal Supranacional, puede conducir a equívocos a la hora de destacar su trascendencia.

El primer aserto no nos parece correcto.- La noción de principio esta referida en el capitulo I del tratado de Asunción, cuando se habla de "objetivos, funciones y principios".- Si se parte del supuesto metodológico de que su ubicación tuvo algún propósito; si se constata su estructura normativa, y si se verifica su conformación como juicios deontológicos prima facie, es evidente que hay principios.

El articulo 3 del Tratado dice que los principios se tendrán en cuenta "en la aplicación ..." y "en la evolución hacia un objetivo final" . Es decir que tanto en el derecho originario como en el derivado deben tenerse en cuenta estos principios, con las funciones que les hemos asignado.

En cuanto al órgano de aplicación es claro que si hubiera un tribunal comunitario habría un mejor desarrollo y una estructura mas clara; objetivo este que depende de la conformación que tenga ese tribunal.- No obstante, estas normas fundantes están dirigidas al legislador, al juez, a los Estados partes y a los particulares.- En cualquier conflicto que se produzca y que deba ser resuelto, aun por los tribunales nacionales, esos principios pueden ser invocados.-
Seguidamente haremos una descripción no exhaustiva de estas normas.-

\section{Principios Juridicos en el \\ Derecho del Mercosur}

Siguiendo las pautas antes fijadas, estudiaremos algunas de las principales normas recibidas en el derecho del Mercosur.-

\section{Principios estructurales:}

Estos principios son mencionados como presupuestos esenciales para el proceso de integración.- Se trata de los pilares básicos sin los cuales el proceso no tendría las características axiológicas que el ordenamiento pretende.- Es muy evidente que un vínculo de cooperación puede tener varios rostros, distintos balances entre valores diversos y disímil será la vida de los individuos según la elección que se haga.Estos principios suponen que la elección se ha hecho y definen una vínculo con determinadas características.-

Son estructurales en el sentido de que conforman la integración, forman parte de ella, son sus pilares.- No tienen un destinatario especifico, sino indeterminado, de modo tal que todos los sujetos resultan obligados.-

Mediante estos principios la integración tiene fisonomía axiológica.-

De ahí su carácter profundamente delimitativo de la actividad legisferante, judicial, y de la actuación privada.-

En una primera impresion, parece excesivo disponer unos principios que son 
anteriores a la integración misma.- Sin embargo, la historia justifica estas prevenciones, de manera que los Estados partes han resuelto "atarse" de manera tal que no pueda pensarse el futuro sin estos principios.- Lo contrario importara el aislamiento y el ostracismo de la comunidad jurídica continental.- Se trata sin duda de una atadura similar a la que utilizara Ulises para frenar sus tentaciones frente a las sirenas, lo que constituye, al decir de Elster ${ }^{16}$, una forma de actuación racional imperfecta para superar la propia debilidad.Seguidamente mencionaremos los mas importantes.-

\section{A) Respeto del Orden \\ Democrático}

En el Acuerdo Mercosur-Unión Europea se incluye como fundamento de la cooperación, el respeto de los principios democráticos, calificándoselo como esencial (Art 1 Acuerdo Marco de cooperación del 15-12-95).-

En el derecho constitucional debemos considerar que este principio esta reconocido como presupuesto para la integración en la Constitución Argentina (art. 75, inc. 24 Const. Argentina).- En las demás constituciones no se lo menciona como presupuesto de la integración, pero es la forma de gobierno adoptada por el Estado.-

De tal manera, la democracia como forma de gobierno surge como un principio estructural, se modo que su violación resulta impeditiva y aun excluyente de un Estado-
Parte que suprima esta forma de gobierno. Es una importante decisión del legislador mercosuriano, que frente a una historia de convulsiones y golpes militares en la zona, ha resuelto vincular la integración con la democracia, como una manera de desalentar el regreso al pasado.

No hay integración sin democracia en los Estados Miembros.-

\section{B) Respeto de los derechos humanos}

El Acuerdo Mercosur-Unión Europea se (Acuerdo Marco de cooperación del 15-12-95), menciona en los considerandos su plena adhesión a los propósitos y principios establecidos en la Carta de la Naciones Unidas, a los valores democráticos, al estado de derecho, al respecto y promoción de los derechos humanos.- En el articulo 1 se refiere que el respeto de los derechos humanos fundamentales, tal y como se enuncian en la Declaración Universal de Derechos Humanos, inspira las políticas internas e internacionales de las Partes y constituye un elemento esencial del Acuerdo.-

En el derecho constitucional de los Estados, el tema de lo incluye de maneras distintas.- El articulo 75 de la Constitución Argentina señala que los tratados de integración deben respetar los derechos humanos.- En Paraguay, el artículo 145 de la Constitución de 1992 adopta como principio de la integración "la protección internacional de los derechos humanos ...".En las demás constituciones se lo menciona
16. ELSTER, Jon, "Ulises y las sirenas- Estudios sobre racionalidad e irracionalidad", Fondo de cultura Económica, 1995.- como presupuesto de la forma de gobierno adoptada por el Estado.-

Dentro de la protecciòn de los derechos humanos $y$, dado el estado actual del desarrollo del Mercosur, estimamos que resulta de primordial relevancia :

n.... un estatuto de los derechos del consumidor : en razòn de que es necesario una base de derechos mìnimos a fin de posibilitar una competencia institucionalmente organizada.- Lo contrario es la desregulaciòn salvaje, que se transforma no sòlo en desproteccion humana, sino en ineficiencia econòmica.En el mediano plazo la desregulaciòn produce efectos desvastadores, que no parecen advertir algunos de los "ingenieros" del mercosur.-

$\mathrm{n}$. un estatuto antidiscriminatorio : para las personas que circulan en el àmbito regional, de un paìs a otro, $y$ aùn dentro de regiones, es primordial la igualdad de oportunidades.- Todas las constituciones nacionales del area y los tratados incorporados permiten la adopciòn de una regla antidiscriminatoria.

\section{C) Desarrollo económico con justicia social}

El Tratado de Asunción preconiza que el objetivo es el desarrollo económico con justicia social (Preámbulo).-

En el Acuerdo Mercosur-Unión Europea se (Acuerdo Marco de cooperación del 15-12-95), se dice que la Comunidad concederá una importancia especial y prioritaria a la lucha contra la pobreza y la exclusión social. En este ámbito, los retos son: contribuir a garantizar la participación de las poblaciones marginadas en la economía de mercado, así como un reparto mas equitativo de los ingresos, con el fin de garantizar un desarrollo sostenible, puesto que se trataría de vincular el desarrollo económico al progreso social ${ }^{17}$. En el texto del acuerdo (art. 10 inc. 7) se establece que promoción de los derechos sociales fundamentales, inspira las acciones y medidas promovidas por las Partes en este ámbito".-

\section{D) Protección ambiental}

El Tratado de Asunción preconiza que el desarrollo económico debe hacerse con la preservación del medio ambiente (art. 1 Trat, y art. 2 decreto 3.91).- Los acuerdos sectoriales deben contemplar la preservación y el mejoramiento del medio ambiente (art. 8, Consejo, Decisión 03/91)

En el Acuerdo Mercosur-Unión Europea (Acuerdo Marco de cooperación del 15-12-95) se afirma la importancia que ambas partes atribuyen a los principios y valores recogidos en la Declaración Final de la Conferencia de Naciones Unidas sobre Medio Ambiente y Desarrollo celebrada en Río de Janeiro en junio de 1992, así como la Declaración Final de la Cumbre Social celebrada en la ciudad de Copenhague en marzo de 1995 (considerandos), y se declara "el desarrollo social, y en particular la

17. Conclusiones de la presidencia del Consejo Europeo de Madrid, 15/16 de diciembre de 1995; conf en DROMI, Roberto-MOLINA DEL POZO, Carlos, “Acuerdo Mercosur Unión Europea”, Ed. Cludad Argentina, 1996) 
(art. 10 inc.6) que "la conservación del medio ambiente y de los equilibrios ecológicos sera tenida en cuenta por las Partes en las acciones de cooperación que emprendan".- En el artículo 17

se regula la cooperación en materia de protección del medio ambiente diciendose que:

1.- Las Partes, con arreglo al objetivo de desarrollo sustentable, promoverán que la protección del medio ambiente y la utilización racional de los recursos naturales sean tenidas en cuenta en los distintos ámbitos de la cooperación interregional.

2.- Las Partes convienen prestar especial atención a las medidas que se refieren a la dimensión mundial de los problemas medioambientales.

3.- Esta cooperación podra incluir, de manera particular, las siguientes acciones:

a) intercambio de información y de experiencias, incluyendo las reglamentaciones y normas;

b) capacitación y educación medioambiental;

c) asistencia técnica, ejecución de proyectos conjuntos de investigación $y$, cuando proceda, asistencia institucional."

La protección del medio ambiente está reconocida en las constituciones de los países miembros.- Así en Argentina, el articulo 41 y 42, reconocen el derecho a un ambiente sano y facilitan instrumentos para la protección.- En la Brasileña se establece que la economía se debe ajustar, entre otros principios, a la defensa el medio ambiente (art. 170, inc. VI), y en el articulo 225 establece una exhaustiva disciplina ambiental.- Se reconoce el derecho a un ambiente sano, se imponen deberes al Poder Publico, se dispone el estudio de impacto ambiental previo a la instalación de una empresa potencialmente peligrosa, y otros aspectos que hacen a la protección ambiental.- La Constitución del Paraguay también tiene dispositivos ambientales similares en los artículos 7 y 8 , que reconocen el derecho a un ambiente sano, prohibición de ingreso de residuos tóxicos, regulación de actividades potencialmente lesivas.-

\section{E) Transparencia en el Mercado}

El Tratado de Asunción preconiza que el objetivo es "asegurar condiciones adecuadas de competencia entre los Estados Partes" (art 1), y se ha dicho que el objetivo de los acuerdos sectoriales es "preservar la transparencia de las reglas del mercado, respetar las prácticas leales de comercio y no perjudicar la oferta en términos de cantidad, calidad y precios, en relación a los usuarios y consumidores" (Consejo Mercado Común, 3-91 ; consid 8).-

El Tratado de Montevideo de 1980 declara que "los acuerdos de complementación económica tienen como objetivos, entre otros, promover el máximo aprovechamiento de los factores de la producción, estimular la complementación económica, asegurar condiciones equitativas de competencia, facilitar la concurrencia de los productos al mercado internacional e impulsar el desarrollo equilibrado y armónico de los países miembros" (art.11, Tratado de Montevideo de 1980).
En el Acuerdo Mercosur-Unión Europea (Acuerdo Marco de cooperación del 15-12-95, art. 4, punto 3) se afirma que la cooperación abarcará principalmente los siguientes ámbitos: el acceso al mercado, la liberalización comercial (barreras arancelarias y no arancelarias), practicas restrictivas de la competencia.-

\section{Principios procedimentales}

Estos principios se refiere al procedimiento de la integración estableciendo de qué manera se avanza. Obligan a los Estados Partes.-

\section{A) Gradualidad:}

El preámbulo del Tratado de Asunción establece que la complementación debe tener su base "en los principios de gradualidad, flexibilidad y equilibrio".-

La integración es un proceso y como tal se hace por etapas.-

Definido el objetivo final, cual es el mercado común o la comunidad, se puede arribar a ella de distintás maneras, y más o menos rápido.- El legislador establece faros, limites, que guían este proceso mediante los principios referidos.-

De ello deducimos que no puede haber saltos abruptos que produzcan desequilibrios en las economías de los Estados Partes y que toda medida debe perseguir el objetivo final, pero sin provocar las crisis de los grandes cambios.-

Paso por paso y manteniendo el equilibrio.

\section{B) Reciprocidad: supresión del}

principio protectorio de

países de menor desarrollo.-

El articulo 2 del Tratado de Asunción señala que el Mercado Común esta fundado en la reciprocidad de derechos y obligaciones.

En Paraguay, el artículo 145 de la Constitución de 1992 señala que "la República del Paraguay, en condiciones de igualdad con otros Estados, acepta el derecho internacional"

La reciprocidad importa la interdependencia de las obligaciones internacionales en un plano de igualdad.Esta es concebida prioritariamente como "igualdad ante la ley", y resulta una consecuencia ineludible de la soberanía nacional implicada en la celebración de los tratados, que impide aceptar un principio contrario.-

Sin embargo, pueden postularse excepciones en el plano de la igualdad material.-

El proceso integrativo se enfrenta con Estados de distinto desarrollo relativo, y consecuentemente con una desigualdad real.- Para equilibrarlo se han ensayado variados instrumentos.- Uno de ellos, utilizado en la Comunidad Europea, es basado en "distintas velocidades" en la implementación de los requisitos necesarios para alcanzar el estatus comunitario.

Otro de los instrumentos es el que podemos denominar "principio protectorio de países de menor desarrollo relativo", que se ha aplicado en nuestro ámbito. 
En el Acuerdo de Cartagena (cap. XIII, arts. 91 a 108) y luego en el tratado de Montevideo de 1980, se estableció el trato especial y diferenciado para socios de menor desarrollo económico relativo (cap. III).- En el preámbulo del Tratado de Montevideo de 1980 se señala que son concientes de que es necesario asegurar un tratamiento especial para los países de menor desarrollo económico relativo. Luego, en el articulo 3, incisio d) - se habla de tratamientos diferenciales para tres categorías de países según su desarrollo, manteniendo un tratamiento mas favorable para los países de menor desarrollo económico relativo.- Finalmente, se le dedica 1 capitulo III al sistema de apoyo de países que se encuentran en esa situación.

La aplicación de este principio consiste en el otorgamiento de condiciones mas favorables, "basandose en los principios de la no reciprocidad y de la cooperación comunitaria".-

El Tratado de Asunción no adopta este criterio y se inserta en la nueva tendencia internacional de remarcar los derechos y obligaciones de los Estados-parte de cualquier convenio en un plano de igualdad.-

\section{C) Solidaridad:}

En el ámbito de la Comunidad Europea se ha desarrollado el principio de la solidaridad, principalmente a través de aplicaciones efectuadas por el Tribunal de Justicia.- Así sucedió cuando un Estado se niega a cumplir con sus obligaciones hacia el resto o bien cuando adopta decisiones

individuales que se contraponen al interés común.- En ausencia de otras normas obligatorias, este principio es una válvula de cierre del sistema comunitario, en la medida en que del mismo se desprende una obligación de obrar teniendo en cuenta el interés comunitario.-

En la sentencia del 7 de febrero de 1973 (Asunto 39/72 Comisión Italia, Rec. 1973 , p. 115 y ss.) el Tribunal afirma que el tratado de integración comunitario otorga ventajas e impone obligaciones, y que cuando un Estado antepone su interés nacional, el equilibrio se rompe.- Agrega luego que ello es una falta a los deberes de solidaridad aceptados por los Estados miembros por el hecho mismo de su adhesión a la Comunidad y afecta a las bases esenciales del ordenamiento jurídico comunitario

Por derivación de este principio, el Tribunal ha censurado la posibilidad de que un Estado miembro celebre acuerdos individuales con otros Estados no miembros.- También ha indicado que los Estados son "como gestores del interés común" en los sectores que son de competencia comunitaria.-

En el ámbito del Mercosur no hay una recepción expresa de este principio. No obstante se lo ha invocado por parte de la doctrina para plantear la situación de Bolivia. - En efecto, este país pertenece al Pacto Andino y busca integrarse en el Mercosur, lo que plantearía una presunta incompatibilidad al pertenecer a dos sistemas competitivos entre $\mathrm{si}^{18}$.

Sobre este tema ampliar en DROMI-EKMEDJIAN-RIVERA, "Derecho Comunitario", Ed. Ciudad Argentina, pág 233 y ss.- ORTUZAR ANDECHAGA, Luis, "Aplicación judicial del derecho comunitario", Madrid, Trivium, 1992.

\section{Principios relativos a la} persona:

\section{A) Carta de derechos}

fundamentales: las fuentes en el ámbito del Mercosur.-

No hay actualmente, en el ámbito del Mercosur, una carta de derechos fundamentales con fuente en el Tratado y el derecho derivado, de la que pueda deducirse la existencia de derechos subjetivos para el ciudadano.- Esta es una idea que se ha desarrollado con fuerza en el ámbito de la Comunidad Europea, incluyendose en el proyecto de Constitución de la Unión Europea, una enumeración de derechos fundamentales compatible con los demás instrumentos internacionales aplicables y los que se derivan de las disposiciones constitucionales nacionales.

Sin perjuicio de su inexistencia como derecho de la integración o comunitario, existen en cambio, la Convención Americana de Derechos Humanos, los principios juridicos que se derivan de ella y de los derechos nacionales, y una cantidad importantes de tratados sobre derechos humanos, que son aplicables a los Estados Partes.

De ese plexo normativo es posible deducir un catalogo de derechos fundamentales, la mayoría de los cuales se encuentran reconocidos en los derechos nacionales-

\section{B) Principales derechos reconocidos}

Los derechos reconocidos en estos tratados son numerosos.- Algunos conceden prestaciones negativas, como la libertad, la igualdad ante la ley, otros otorgan prestaciones positivas, como el derecho a al trabajo.- En todos estos casos, resultan legitimados pasivos el Estado Nacional, o el ciudadano o grupos que lesionan estos derechos.-

La temática es muy variada.Haremos seguidamente una enunciación general, para luego referir mas específicamente a los que tienen alguna característica especial en el derecho de la integración:

- La igualdad ante la ley y prohibición del trato discriminatorio basado en distinciones de raza, color, sexo, idioma, religión, opiniones políticas, origen nacional o social, posición económica, nacimiento o cualquier otra condición social.-

- Derecho a la vida, a la integridad física, a la seguridad, la libertad de investigación, a la protección de la honra y la vida privada, derecho al nombre.Libertad de expresión, libertad de conciencia, derecho de rectificación y respuesta.-

- Derecho a la protección de la familia, de la maternidad, de la infancia, los derechos del niño.-

- Derecho al debido proceso, a la protección contra la detención arbitraria, al asilo.-

- Derecho de residencia y de transito, a la inviolabilidad del domicilio y de la correspondencia,

- Derecho a la educación, a la cultura, al trabajo en condiciones dignas, al descanso, a la seguridad social, 
- Derecho de propiedad, derecho al reconocimiento de la personalidad jurídica, de justicia. de asociación,

- Derecho a la nacionalidad el gobierno

Derecho a reunirse, a participar en

Asimismo, hay derechos con titulares especiales.- Los mas importantes son las convenciones referidas a la mujer y al niño, de amplia ratificación en el ámbito latinoamericano.

La "Convención sobre la Eliminación de todas las formas de discriminación contra la mujer" compromete a los Estados a eliminar la discriminación contra la mujer, asegurar el principio de igualdad entre el hombre y la mujer y garantizar la aplicación tal principio, eliminando la idea de inferioridad o superioridad de los distintos sexos y la discriminación contra la mujer en lo relativo al matrimonio y a las relaciones familiares. - Dispone asimismo los mismos derechos a los cónyuges en materia de propiedad, compras, gestión, administración, goce y disposición de los bienes (art. 16, inc. 1, h); el derecho a elegir apellido (art. 16, inc. 1, g.); la carencia de todo efecto jurídico de los esponsales (art. 16, inc. 2); los mismos derechos para ambos padres respecto de sus hijos (art. 16, inc. 1, d),

La Convención de los derechos del niño declara el derecho a conocer a sus padres y a ser cuidado por ellos (art. $7^{\circ}$ ), a no ser separado de sus padres y mantener contacto con ellos cuando deba estarlo (art 99), la responsabilidad de los padres respecto de la crianza y el desarrollo del niño teniendo en cuenta el interés de este (art. 18).-

Excede los limites de este trabajo la realización de una enumeración exhaustiva de los derechos, por lo que nos concentraremos en algunos de ellos que tienen mayor aplicación en la etapa actual del Mercosur.

\section{La libertad de circulación}

\section{A) General y especial}

Para tratar este tema debe distinguirse entre la libertad como postulado que se predica respecto del individuo, y el ejercicio de la misma.- El primer aspecto es, según muchos autores, prejurídico, en el sentido de que la norma no podría anularlo, ni siquiera limitarlo.- Sin introducirnos en ese debate, es necesario aclarar que las normas que trataremos se refieren en realidad al ejercicio de la libertad.-

No obstante, aún el ejercicio de la libertad es un termino que, para el Derecho, tiene muchos significados diferentes.Tomando como ejemplo el derecho argentino, vemos que la Constitución Nacional se propone "asegurar los beneficios de la libertad" (Preámbulo) y señala (art. 19) que "las acciones privadas de los hombres que de ningún modo ofendan al orden y a la moral pública, ni perjudiquen a un tercero están sólo reservadas a Dios y exentas de la autoridad de los magistrados.- Ningún habitante de la Nación será obligado a hacer lo que no manda la ley, ni privado de lo que ella no prohibe".- Asimismo dispone (art. 42) que los consumidores y usuarios tienen derecho en la relación de consumo a "la libertad de elección" , y (art. 32) que no se dictarán leyes que "restrinjan la libertad de imprenta".- El Código Civil dispone (art. 53) con referencia a las personas de existencia visible, que: "Les son permitidos todos los actos que no les fueren expresamente prohibidos, independientemente de su calidad de ciudadanos y de su capacidad política".

En virtud de ello se ha distinguido entre una libertad general y libertadas especiales.- Estas ultimas son las que se analizan en relación a determinados bienes y derechos: libertad de prensa, de circulación, de expresión.- A su vez, hay libertades que están vinculadas a la esfera intima del sujeto y otras a la esfera privada ${ }^{19}$.

En nuestro caso analizaremos el ejercicio de algunas de las libertades especiales que tienen relación directa con la etapa actual de la integración en el Mercosur.-

\section{B) La libertad de circulación}

El Tratado de Asunción establece en su articulo 1 que el Mercado común implica la libre circulación de bienes, servicios y factores productivos.-

De tal manera, el principio general de la libertad aplicado a la circulación interestatal, tiene importantísimas consecuencias en planos muy diversos:

- Significa una erosión de las barreras fronterizas, las que tienden a decaer

19. conf "Las normas fundamentales de Derecho Privado". progresivamente, desmontándose los obstáculos legales que impiden, limitan o restrinjen el ejercicio de la libertad.-

- Acarrea una redefinición progresiva del término "extranjero" y todo el andamiaje jurídico construido alrededor del mismo.Una verdadera libertad de circulación requiere un trato similar al nacional, y un debilitamiento de la "extranjería".

- Se produce una inversión del sistema tradicional que limita la entrada a un país. - La regla comienza a ser la libertad de circulación, mientras que toda excepción debe justificarse razonablemente, so pretexto de ser considerada arbitraria.-

En este aspecto, la libertad se vincula con la circulación de los trabajadores, de la empresas, de los profesionales autónomos, y de los bienes, algunas de las cuales veremos más detenidamente en la parte especial.-

\section{C) El domicilio y la libertad de circulación}

En un mercado común que se propone incrementar la circulación de las personas, tiene una gran trascendencia la cuestión del domicilio, sobre todo relacionado con las limitaciones fundadas o arbitrarias, que un sujeto puede sufrir en función del mismo.-

En el Derecho Privado se afirma que el domicilio es uno de los atributos de la personalidad. - Como consecuencia de ello deviene una facultad que es la libertad de elección del mismo por parte del sujeto titular.- 
Esta regla se enlaza con otros aspectos que la limitan atendiendo a otras razones.En el ámbito internacional, hay que considerar que el domicilio es tomado en cuenta como un punto de conexión para la determinación de la competencia judicial.Puede haber diferencias en la definición del domicilio que resulten restrictivas de la libertad de circulación.-

Uno de los aspectos que mas conflictividad genera es la constitución de domicilios en países distintos al de nacimiento.- El derecho a hacerlo se inscribe dentro de la libertad de circulación.- En el ámbito de la Union Europea se dictó la directiva 68/360 que dispuso que los Estados miembros suprimieran las restricciones al desplazamiento y a la residencia para sus nacionales y los miembros de su familia.-

En el acuerdo para facilitación empresaria celebrado entre Argentina y Brasil, se ha hecho un avance importante en este sentido y nos referiremos al mismo al tratar las sociedades.-

\section{La igualdad ante la ley vigente en los Estados \\ Partes}

\section{A) La igualdad ante la ley:}

Los derechos nacionales preveen la igualdad con rango constitucional.- El articulo 1 de la Constitución Brasileña establece que "todos son iguales ante la ley, sin distinción de cualquier naturaleza, garantizándose a los brasileños y a los extranjeros residentes en el país, el derecho a la vida, a la libertad a igualdad, a la seguridad y a la propiedad..." La Constitución argentina asegura que todos los hombres son iguales ante la ley y no hay prerrogativas de sangre, ni de nacimiento (art. 16 CN), que en la relación de consumo hay un derecho a un trato equitativo (art 42) y que el Congreso debe dictar leyes que "garanticen la igualdad real de oportunidades y de trato" (art. 75 inc. 23). La Constitución del Paraguay prevee la igualdad de los habitantes en dignidad y derechos, indicando que no se admiten discriminaciones (art.46).-

De estas normas se desprende la igualdad ante la ley.-

El ejercicio de la libertad de circulación admitida en los mercados comunes, plantea el problema de si los ciudadanos de un país, al ir a otro EstadoParte, son iguales que los nacionales ante la ley vigente.- En este ultimo caso, qué tipo de igualdad es admisible y cuál es su contenido.-

\section{B) La igualdad de derechos \\ fundamentales básicos:}

Esta igualdad ante la ley, reconocida en los derechos nacionales de los Estados Partes, debe relacionarse con el respeto de los derechos humanos que es admitido como principio jurídico estructural de la integración.-

De este relacionamiento puede deducirse, sin esfuerzo, que hay una igualdad en los derechos fundamentales, que tienen carácter transnacional y que no permiten discriminación en virtud de las nacionalidades.- El respeto a la vida o a la dignidad, no tiene nacionalidades.-
Ello significa que, en supuestos de incompatibilidad de la legislación comunitaria o nacional, con los derechos fundamentales básicos, éstos últimos tienen primacía.

En el ámbito de la Union Europea, el Tribunal de Justicia, en la causa Nold del $14 / 5 / 74$ afirmo que "los derechos fundamentales son parte integrante de los principios generales del derecho cuyo respeto asegura; que el asegurar la protección de estos derechos, el Tribunal debe inspirarse en las tradiciones constitucionales comunes a los Estados miembros, y no puede, por ello, admitir medidas incompatibles con los derechos fundamentales reconocidos y garantizados por las Constituciones de esos Estados; que los instrumentos internacionales, relativos a la protección de los derechos del hombre en que han cooperado los Estados miembros o a los que se han adherido, pueden, asimismo, proporcionar indicaciones que conviene tener en cuenta en el derecho comunitario".-

En Argentina se ha dado un paso importante en este sentido,con la reforma constitucional de 1994.- El texto aprobado de la Carta Constitucional señala que tienen jerarquía constitucional los tratados sobre derechos humanos.- Si bien no integran la Constitución, tienen el mismo valor que sus normas, pero "no derogan artículo alguno de la primera parte de esta Constitución y deben entenderse como complementarios de los derechos y garantías por ella reconocidos (art. 75, inc. 22).- Este aspecto, indudablemente oscuro, ha sido interpretado como una suerte de primacía de ese núcleo de garantías de la primera parte de la Constitución Nacional, en caso de incompatibilidad con algún tratado.-

\section{C) El problema del contenido de la igualdad de los derechos fundamentales:}

¿Que significa la igualdad ante la ley referida a los derechos fundamentales?.- La respuesta involucra dos problemas distintos:

- uno de ellos que todos los ciudadanos pertenecientes a los EstadosPartes tienen la misma posición jurídica respecto de los derechos fundamentales reconocidos en uno de los Estados.-

- el otro aspecto, se relaciona con el grado de satisfacción que un ordenamiento jurídico nacional da a un derecho, y si ése nivel es similar o no al que se obtiene en otro Estado parte.-

El primer aspecto nos introduce, a su vez, en dos cuestiones. - La primera sobre la discriminación entre nacionales y extranjeros como contracara del derecho a la igualdad en materia de derechos fundamentales y en otros aspectos, que veremos en el punto siguiente.-

El segundo tema, que vamos a tratar aquí, es cómo se receptan en los tratados internacionales de derechos humanos y la normativa comunitaria sobre este tema.- No nos podemos extender sobre este arduo problema, pero haremos algunas distinciones, tomando como base la legislación argentina.-

Los tratados sobre derechos humanos, así como el régimen constitucional nacional y la legislación del 
derecho de la integración, en cuanto refieren a este tema, tienen los siguientes efectos:

- Efecto derogatorio: El tratado internacional sobre derechos humanos no puede tener efectos derogatorios de los derechos y garantías de la primera parte de la Carta Magna.- Ello significa que no puede, directa o indirectamente, suprimirse ninguno de ellos.-

- Efecto aditivo: los tratados pueden adicionar derechos al texto constitucional.público:

- Conformidad con el derecho

Este efecto tiene un límite, y está dado por la circunstancia de que esos nuevos derechos deben estar de conformidad con los principios de derecho público establecidos en la Constitución (art. 27 CN).-

- Relación de complementariedad:

En cambio, no se requiere una conformidad con la primera parte de derechos y garantías, sino una relación de complementariedad (art.75 inc.22).- Este vínculo significa en el plano interpretativo que debe buscarse una "armonización", de modo que uno no derogue al otro, ya que este es un efecto prohibido.-

La noción de complementariedad no excluye que un derecho pueda obrar de modo reglamentario respecto de otro.- $\mathrm{Tal}$ es lo que ocurre con el derecho de réplica en relación con la garantía de libertad de prensa, puesto que no la deroga, sino que le establece límites.-

\section{Conclusión:}

En base a ello podemos afirmar:

- hay un plexo de derechos fundamentales de los ciudadanos del Mercosur que se basa en los tratados internacionales y sú recepción interna.-

- todos los ciudadanos de los estados partes son iguales ante la ley en esta materia, y no pueden ser discriminados por razón de su nacionalidad.-

- las variaciones admisibles son aquellas que importan una adecuación de los derechos individuales al orden público nacional, en la medida en que sea una restricción razonable y no se produzca una desnaturalización del derecho.-

Con referencia al segundo problema apuntado, nos plantea cuestiones referidas a los derechos fundamentales tienen un contenido mínimo esencial y si ese mínimo social puede ser comunitario.- Es decir, si puede hablarse de una base de satisfacciones mínimas para todos los ciudadanos del Mercosur.- Indirectamente, es un tema que se relaciona con la armonización legislativa, puesto que al efectuarse este proceso, hay que comparar, necesariamente, cómo se atienden las demandas sociales de los distintos países en materia de derechos básicos, y el costo nacional diferenciado que ello representa en la competencia empresaria trasnacional.-

Es claro que no hablamos aquí del contenido mínimo de los derechos, de una igualdad de recursos, tema que escapa tanto a esta investigación, como al grado de desarrollo de la normativa del Mercosur ${ }^{20}$.

20. sobre el contenido de los derechos, ampliamos en "Las normas fundamentales de Derecho Privado", Ed. Rubinzal y Culzoni, 1995)

Revista da Faculdade de Direito da UFRGS, v. 17, 1999
D) La igualdad entre nacionales y

extranjeros: inversión de la

carga argumentativa en el

derecho de la integración.-

Conforme con la argumentación precedente, se debe admitir que las personas, en cuanto tales, tienen derechos fundamentales básicos transancionales.Mas allá de este piso mínimo hay desigualdades basadas en determinadas calidades de las personas que son consideradas licitas, como el talento, y otras ilícitas, como la raza o la religión.-

En el derecho de la integración, se pone en cuestión el distingo basado en la calidad de "nacional" o "extranjero perteneciente a un Estado-Miembro", que puede presentar una persona física o jurídica.-

En problema es muy importante y hace a la esencia misma de la libertad de circulación y de la constitución de un mercado común.- En la constitución de sociedades, en los subsidios, en las licitaciones publicas, en el acceso a determinados cargos, en el trabajo dependiente o autónomo, hay prioridades para los nacionales de cada país, que se han visto como normales desde la perspectiva del derecho estatal. - Sin embargo, el derecho de la integración ha planteado una reformulación de estos temas, que puede ser examinada como derecho a la igualdad y como derecho antidiscriminatorio, refiriéndose en ambos casos tanto a las personas físicas como jurídicas.-

La primera pregunta es entonces sobre la fundamentación de este distingo.-
Al respecto las normas nacionales son claras.-

La Constitución Argentina establece la igualdad entre nacionales y extranjeros en su articulo 20 al equipararlos en el ejercicio de su industria, comercio y profesión.- No se detiene allí, sino que fomenta la inmigración: el articulo 25, establee que "el gobierno federal fomentara la inmigración europea, y no podra restringir, limitar ni gravar con impuesto alguno la entrada al territorio de los extranjeros que traigan por objeto labrar la tierra, mejorar las industrias, e introducir y ensenar las ciencias y las artes". - La idea inspiradora de estos textos es que Argentina necesita población.-

Siguiendo esta linea, la legislación infraconstitucional ha sido permisiva en el ingreso de extranjeros, sean personas físicas o jurídicas, y actualmente se mantiene una igualdad genérica ante la ley.-

La Corte Suprema de Justicia ha reafirmado esta linea de pensamiento.- En un caso en que una persona pretende que se declare inconstitucional un reglamento educativo que exigía la ciudadanía argentina para el desempeño del cargo de docente, la Corte dijo: "no hay, pues ninguna duda de que, en cuanto al ejercicio de los derechos civiles y, especialmente al desempeño de sus profesiones, dentro de la República, los extranjeros están totalmente equiparados a los argentinos por expresa prescripción constitucional, de donde toda norma que establezca discriminaciones entre aquellos y estos en tales aspectos, estaría en pugna con la antes transcripta prescripción constitucional". - La Corte 
considera discriminatorias estas las que subsistan, deben ser fundadas desigualdades ${ }^{21}$.

La Constitución de Brasil tiene una regla normativa sobre derechos fundamentales básicos, en el articulo cinco, que garantiza a los brasileños y extranjeros residentes, la inviolabilidad del derecho a la vida, la libertad, la igualdad, la seguridad y la propiedad.- La legislación sobre la situación jurídica del extranjero, ya tenia este principio en las leyes 6815/80 y 6964/ 81.

Examinando estas normas puede afirmarse que:

- los nacionales y los extranjeros pertenecientes a los Estados-Miembros son sujetos de derecho con una calidad jurídica distinta, puesto que no se ha suprimido e distingo ni se ha desarrollado la noción jurídica de ciudadanía comunitaria.-

No obstante ello hay un cambio trascendente.- Entre países no integrados las calidades referidas hacen que el trato es, como regla general, diferenciado, salvo excepciones que el Estado nacional debe fundar.- En el derecho de la integración, en cambio, cambia la regla argumentativa: el Estado nacional debe fundar toda regla que disponga un trato distinto.

Ello es así, porque a pesar de subsistir la calidad de nacional y de extranjero, los Estados se obligan a la eliminación de las restricciones arancelarias y no arancelarias para la libre circulación de personas (art. 1 Tratado de Asunción).- Siendo la regla normativa la eliminación de barreras, todas

especialmente.

El trato diferente para un extranjero perteneciente a un Estado miembro es una barrera para la circulación, y su mantenimiento debe ser razonablemente fundado. - Una fundamentación es irrazonable si sólo se sostiene solo en la calidad de extranjero, miembro de un Estado-Parte.-

Asimismo, los derechos de los extranjeros pertenecientes a un Estado Miembro tienen una calidad especifica: debe ser tratados de un modo igual al nacional.-

De ello surge claramente la contracara: toda distinción basada en la pertenencia a un Estado-miembro, es arbitraria o ilegitima.

\section{6) El principio}

antidiscriminatorio:

\section{A) Concepto legal:}

Tanto la libertad como la igualdad, como principios han dado lugar a planteos relativos al derecho a no ser discriminado.-

La discriminación tiene varias definiciones legales.- La Convención Americana sobre Derechos Humanos establece (art. 1) que el ejercicio de los derechos debe ser garantizada "sin discriminación alguna por motivo de raza, color, sexo, idioma, religión, opiniones políticas o de cualquier otra índole, origen nacional o social, posición económi-

21. "Repetto c. Pcia de Bs.As."- Ver comentario a este fallo en Miller- Gelli-Cayuso", Constitución y Derechos Humanos", Astrea, Bs As, 1991, t.2)

Revista da Faculdade de Direito da UFRGS, v. 17, 1999 ca,nacimiento o cualquier otra condición social".

En Argentina, los arts 16 y 20 prohiben las distinciones basadas en la sangre, nacimiento, nobleza y nacionalidad.- El artículo 1 de la ley 23592 dispone que "quien arbitrariamente impida, obstruya, restrinja o de algún modo menoscabe el pleno ejercicio sobre base igualitarias de los derechos y garantías fundamentales reconocidos en la Constitución Nacional, será obligado a pedido del damnificado a dejar sin efecto e acto discriminatorio o cesar en su realización y a reparar el daño moral y material ocasionados".

En Brasil,la Constitución establece la prohibición de distingos basados en la nacionalidad (art 5), sexo (art. 5,I), raza (art.5, XLII), diferencias admisión en e empleo basadas en sexo, edad, o estado civil (art 7, XXX)

Desde el punto de vista legal hay bastante coincidencia en la

definición del principio antidiscriminatorio.

\section{B) La discriminación como problema en el derecho de la integración:}

En el ámbito de la integración, es sin duda la nacionalidad la que puede motivar mayores conflictos en materia de trato discriminatorio.

En los derechos nacionales, la idea de dicriminación encuentra su campo más fértil cuando las personas físicas son tratada desigualmente con un fundamento irrazonable, como el sexo, la religión o las ideas políticas.-

En el derecho de la integración, en cambio, la circulación de personas entre países distintos, pero integrados, pone en primer plano el trato desigual fundado en la nacionalidad. - Además, en el derecho de la integración, la discriminación se puede aplicar también a las personas jurídicas, y principalmente a la actividad empresaria que se desarrolla en uno y otro país, siendo tratada inequitativamente.-

De manera que el principio antidiscriminatorio es un instrumento muy idóneo para instar a la igualdad entre personas físicas o jurídicas de los Estados Miembros.- Su mayor relevancia radica en que la discriminación es un aspecto que generalmente lo visualiza el afectado, y es él quien lo plantea, de modo tal que actúa como un modo de control sobre la noción de igualdad que se sostiene de los ámbitos públicos.-

Este aspecto de la cuestión ha motivado una gran actividad judicial, principalmente en el ámbito de la Comunidad Europea, por lo que mencionaremos brevemente esta experiencia, para luego examinar los conceptos juridicos aplicables.-

\section{C) La discriminación en el mercado común: la experiencia de la union europea.}

En el ámbito de la Union Europea, el tema de la discriminación ha sido tratado con amplitud, aun en el período de transición inicial, como el que vive ahora 
el Mercosur.- Mediante normas referidas a la etapa liberalización progresiva, en el art. 7 이 del Tratado de Roma se prohibe "toda discriminación por razón de la nacionalidad" como regla general.-

Esta regla general tiene aplicaciones muy especificas en el comercio.- Por ejemplo, se ha establecido:

- que la política agrícola común, debe lograrse excluyendo "toda discriminación entre productores y consumidores de la Comunidad" (arts 39/40).

- que la liberalización progresiva de las barreras para la libertad de establecimiento y libre prestación de servicios, deben hacerse sin distinción de nacionalidad o residencia (art. 65).-

- que los Estados deben garantizar la igualdad de remuneración, sin distinción por razones de sexo (art. 119).-

- que la "la libre circulación supondrá la abolición de toda discriminación por razón de la nacionalidad entre los trabajadores de los estados miembros, con respecto al empleo, la retribución y las demás condiciones de trabajo" (art. 48 inc.2).-

El principio antidiscriminatorio se aplicó también para desechar criterios aparentemente objetivos que de hecho conducen a una forma disimulada de discriminación. Tal es el caso de la sentencia del 16-2-1978, as. 61/77 y 88/77 en relación a las medidas tomadas por la República de Irlanda, prohibiendo el acceso de su zona de pesca a los barcos de un tamaño potencia superior a ciertos limites, que de hecho excluía una buena parte de la flota de pesca de otros Estados miembros, pero no la flota irlandesa. .

A modo de criterio de juzgamiento genérico, en una sentencia del 4-2-1982 se afirma que la discriminación consiste en tratar de idéntica manera situaciones que son diferentes, o de modo diferente situaciones que son idénticas. Por tanto, no hay discriminación cuando el legislador trata de forma no idéntica a funcionarios jubilados y en activo, ya que ambas situaciones difieren sensiblemente.-

\section{D) El principio \\ antidiscriminatorio en el mercado:}

El principio antidiscriminatorio está también vinculado con el derecho de acceso a actividades económicas por parte de personas físicas y jurídicas de origen extranjero.- Establecido que en un mercado integrado hay libertad de circulación, se produce una tendencia al trato igualitario entre las sociedades y personas físicas de los países miembros.- Este trato suele ser expresado mediante un derecho de trato igualitario como nacional.-El reverso de este derecho se da cuando un país trata a una sociedad de otro país, de un modo distinto a sus nacionales, basandose solo en razones de nacionalidad.-

El contenido de la discriminación en este aspecto se vincula con:

- la imposición a los extranjeros, de restricciones de acceso al mercado nacional distintas de las que deben cumplir los súbditos.-
- la existencia de un tratamiento jurídico para nacionales y otro distinto para extranjeros en cuanto al disfrute de los derechos vinculados al acceso.-

Dentro de estos parámetros, en el ámbito de la Union Europea se han considerado discriminatorias ${ }^{22}$ las prohibiciones de acceso para extranjeros a un mercado nacional determinado, la exigencia de condiciones adicionales respecto de los nacionales, el requerimiento de una estancia previa en el país para gozar de igualdad, la imposición de cargas fiscales especiales, o la constitución de una fianza, o cargas que hacen más oneroso el aprovisionamiento o las posibilidades de venta.- También lo son aquellas disposiciones que subordinan a condiciones particulares para extranjeros la presentación de ofertas, licitaciones, la adquisición de bienes muebles o inmuebles, o el acceso al credito.-

\section{E) Su aplicación en materia \\ societaria:}

En materia de sociedades, el principio antidiscriminatorio es particularmente útil.-

El otorgamiento de la calidad de persona a una sociedad es un acto estatal; el reconocimiento de dicho acto en un Estado Extranjero, es un acto de soberanía estatal por parte de este ultimo.- De modo que es perfectamente legitimo que un Estado establezca condiciones para decidir si admite, y con qué requerimientos, un acto normativo estatal extranjero referido a la

22. conf GOLDMANN, Berthold, LYON CAEN, Antoine, "Derecho comercial europeo", pág. 214 23. GOLDMANN- LYON CAEN, op cit, pág 110. creación jurídica de personalidad societaria.-

En principio la sociedad debe haber sido creada con arreglo a las normas del Estado de origen.- Este requisito, que ha sido denominado "necesidad de un vínculo jurídico entre la sociedad y el Estado extranjero", significa que debe respetar los procesos sustantivos y formales de constitución y el orden público nacional de origen.-

Para el juzgamiento de este tema, se ha efectuado una cierta analogía entre la nacionalidad de las personas físicas y las de las sociedades ${ }^{23}$, de allí que debe dar todos los pasos para ser considerada "sociedad nacional".- Esta caracterización referida a la nacionalidad, ha dado lugar a muchos debates en materia societaria, pero en a los efectos del principio discriminatorio, no es necesario establecer una "nacionalidad" societaria, sino simplemente, establecer si los criterios aplicables al trato discriminatorio entre personas físicas nacionales y extranjeras, es aplicable por analogía a las personas jurídicas.-

En este campo, no puede haber duda alguna de las analogías y de la aplicación del principio referido.-

Naturalmente, con esta afirmación no se solucionan los problemas, sino que comienzan, puesto que hay que hacer muchas distinciones a fin de apreciar adecuadamente los intereses societarios en la competencia igualitaria y los de los Estados Nacionales. 
Generalmente, estos matices comienzan por el reconocimiento de las sociedades extranjeras. - El reconocimiento tiene por efecto admitir la capacidad jurídica de la sociedad.- Esta capacidad puede ser admitida de un modo igual que la de las nacionales o bien incorporarse algunos requisitos especiales, por el hecho de tratarse de una sociedad extranjera.-Ello nos lleva a la necesidad de evaluar cuales son admisibles y cuales lesionan el principio antidiscriminatorio.

\section{F) Discriminación de hecho:}

Este concepto surge a partir de situaciones legales de igualdad, pero que consagran impedimentos fácticos insalvables, cuyo resultado lleva a una desigualdad real.-

Ello sucede cuando un Estado establece la igualdad de acceso al mercado por parte de nacionales y extranjero, pero requiere a estos últimos, por ejemplo, la presentación de títulos universitario expedidos por universidades nacionales ${ }^{24}$. De esta manera un profesional extranjero debería hacer nuevamente su carrera o bien rendir equivalencias, lo que constituye un obstáculo muy fuerte a la entrada al mercado, basado en la extranjería.-

La solución no discriminatoria es exigir títulos expedidos por el Estado extranjero de similar valía, o bien homologados, o bien controlados de alguna manera por el Estado Nacional.-

\section{G) Discriminación positiva:}

Este procedimiento ha sido llamado de diversas maneras: acción afirmativa,

24. sobre este caso ver GOLDMANN- LYON-CAEN, pág. 139 discriminación inversa, rebasamiento del tratamiento nacional.- Se refiere a que, en muchos casos, el Derecho trata mejor al extranjero que al nacional para superar obstáculos de hecho.-

Esta acción resulta legitima siempre que arribe a una igualdad fáctica final, y no a una discriminación en perjuicio de los nacionales.

\section{H) Restricciones no \\ discriminatorias:}

Es legitimo que una sociedad extranjera deba cumplir requerimientos especiales o incluso modificar aspectos societarios si ellos son requeridos también para las nacionales. - Por ejemplo, en materia de participación en actividades financieras, asegurativas, de salud, y muchas otras, las sociedades nacionales deben tener un determinado tipo societario, cumplir requerimientos de solvencia, y muchos otros que responden al orden público o a la protección de los consumidores y que pueden ser exigidos por igual a nacionales y extranjeros.-

La razón de la exigencia no es la nacionalidad, sino el orden público, y éste se exige por igual a nacionales y extranjero, sin ser usado como un modo de discriminar.-

\section{I) Discriminación contra las sociedades nacionales:}

La adopción de regulaciones societarias no debe generar una discriminación inversa, que ponga en peor situación a los nacionales respecto de los extranjeros. - Es claro que los Estados deben ir derogando las trabas nacionales respecto de la libre circulación, pero estas libertades de origen nacional o comunitario, también pueden ser invocadas por las empresas nacionales.-

De manera que una sociedad nacional puede invocar esta discriminación contra nacionales en ciertas medidas que la posicionen desventajosamente en el mercado.-

\section{J) Sujetos con poder \\ discriminatorio}

El acto discriminatorio puede ser llevado a cabo por los Estados a través de sus políticas publicas. - Sin embargo, siendo lo mas frecuente, no es el único caso.- Los actos que llevan a cabo entidades no gubernamentales que ejercen funciones delegadas, pueden ser discriminatorios.-

En este sentido se expidió el Tribunal de Justicia de la Union Europea cuanto tuvo que censurar una decisión emanada de los reglamentos de actividades deportivas de un Estado miembro que excluyen a los súbditos de otro Estado miembro estableciendo la siguiente doctrina: "la abolición entre los Estados miembros de los obstáculos a la libre circulación de personas ...se vería comprometida si la abolición de las barreras de origen estatal pudiese ser neutralizada por asociaciones $u$ organismos no dependientes del derecho público mediante obstáculos derivados del ejercicio de su autonomía ${ }^{25}$.
K) El principio no discriminatorio en materia fiscal

La no discriminación en la circulación de bienes y servicios implica que se deben adoptar normas que impidan la distorsión de la competencia, tanto en el nivel nacional como en el comunitario, comprometiendose los Estados Miembros a su cumplimiento (art. 5, TR).-

Un aspecto relevante de este tema es la perspectiva que tiene para los consumidores. - En este sentido se ha señalado ${ }^{26}$ que "debe darse cumplimiento al principio de la no discriminación enunciando en el articulo 7 del Tratado, en cuanto que a los adquirientes les debe resultar indiferente desde el punto de vista fiscal comprar un bien nacional o importado de otro país miembro. Se trata de prohibir cualquier clase de proteccionismo mediante la aplicación de impuestos interiores; es decir, de aquellos que discriminen los bienes locales de los importadores, en cualquier fase de fabricación o circulación".-

\section{L) Nombre y trato discriminatorio}

Tradicionalmente el nombre fue concebido como un elemento para la identificación del potencial humano nacional.- Sin embargo, desde hace un siglo la doctrina y la legislación ha postulado que es un atributo de la personalidad ${ }^{27}$.-

De tal modo, es un derecho a la identidad personal estática.- Se diferencia

25. CJCE.12.12.74, citada por Goldmann, pág. 218

26. AMERISO, Claudia Cristina, "Coordinación de politicas tributarias para la consitución del mercado ampliado", público en "mercosur, ..", dir por Ciuro Caldani, Ed. Ciudad Argentina, pág. 87.-

27. Sobre este tema ampliar en: RIVERA, Julio, Instituciones de Derecho Civil", Abeledo Perrot, Bs.As., 1994; PLINER, Adolio, "El nombre de las personas", Abeledo Perrot, Bs.As. 1989. 
de la identidad dinámica en que esta no alude al nombre, sino al modo en que un individuo es conocido por otros en virtud de sus actuaciones en la vida social.-

El nombre es entonces un derecho a la identidad, desde el punto de vista privado y un deber identificación, desde la perspectiva publica ${ }^{28}$.

El nombre se relaciona con el principio antidiscriminatorio y el derecho de la integración, cuando es utilizado como impedimento para la libre circulación o la igualdad de oportunidades.

En la Union Europea, el Tribunal de Justicia ha resuelto que constituye una discriminación fundada sobre la nacionalidad y una traba al derecho de libre establecimiento, la inscripción en el Registro del estado civil de un Estado miembro de un ciudadano de otro Estado miembro, con un grafismo tal que la pronunciación del nombre se encuentra modificada y deformada, y que esa deformación que resulta lo expone al riesgo de una confusión de personas con relación a su clientela.-

\section{7) Principios de derecho privado común latinoamericano}

Conforme ya lo hemos expuesto, el Tratado de Asunción demanda la armonización de las legislaciones.- Este es un proceso lento y complejo.- Una parte fundamental del mismo consiste en identificar principios juridicos comunes a los derechos nacionales.-

En el ámbito del derecho privado se han identificado los siguientes: la fuerza vinculante de los contratos (art. 1197 Cód. Civ. Argentino; art. 1291 Cód. Civ. Uruguayo y art. 715 Cód. Civ. Paraguayo), buena fe (art. 1198 Cód. Civ. Argentino; art. 131 Cód. Com. y Cód. del Consumidor Brasileño; art. 1291 Cód. Civ. Uruguayo; arts. 372, 689 y 715 Cód. Civ. Paraguayo) abuso del derecho (art. 1071 Cód. Civ. Argentino; art. 372 Cód. Civ. Paraguayo), enriquecimiento sin causa (art. 1038 Cód. Civ. Uruguayo y art. 1817 Cód. Civ. Paraguayo) y reparación integral (arts. 1109 y 1113 Cód. Civ. Argentino; art. 150 Cód. Civ. Brasileño; art. 1319 Cód. Civ. Uruguayo y arts. 421, 450/53 Cód. Civ. Paraguayo), adecuación del contrato (art. 1198, 2o párrafo, Cód. Civ. Argentino, art. 1291, 2o párrafo, Cód. Civ. Uruguayo y arts. 671/672 Cód. Civ. Paraguayo) y protección del débil jurídico (art. 954 Cód. Civ. Argentino y art. 3 ley 24.240 argentina; Cód. del Consumidor Brasileño; arts. 671 y 691 Cód. Civ. Paraguayo) ${ }^{29}$.

\section{El Derecho Derivado}

En el ámbito del derecho derivado podemos indicar las siguientes tipologías normativas que son establecidas en el Tratado de Asunción y en el Protocolo de Ouro Preto.-

28. Sobre esta concepción ampliamos en:"Constitucionalización del derecho civil y derecho a la identidad personal en la doctrina de la Corte Suprema", LL. 10.8.93.-

29. HIGHTON, Elena - LAMBOIS, Susana, Unificación y efectividad del derecho en los países del Mercosur, en "Rev. de Derecho Privado y Comunitario", ne 6, p. 448; FRESNEDA SAIEG, Mónica, FRUSTAGLI, Sandra, ESBORRAZ, David, HERNANDEZ Carlos, "Hacia la unificación del derecho de las obligaciones y de los contratos en el Mercosur".

\section{A) Decisiones:}

Las decisiones son actos normativos emitidos por el Consejo del Mercado Común para la conducción política del Mercosur, de alcance obligatorio para los Estados Partes.-

Son actos normativos en el sentido de que contienen mandatos, prohibiciones y permisiones.-

Están previstas en el art. 16 del Tratado de Asunción que refiere a las "decisiones" del Consejo de Mercado Común y del Grupo Mercado Común.- El Protocolo de Brasilia para la solución de controversias se refiere a "las decisiones del Consejo del Mercado Común" (art. 1). El Protocolo de Ouro Preto establece que "el Concejo del Mercado Común pronunciara mediante Decisiones..." (arts. 9o y 41).

De acuerdo con estos documentos, las decisiones son actos adoptados por el Concejo del Mercado Común para el cumplimiento de las funciones que le otorgan los arts. 10 del Tratado de Asunción y 30 y $8^{\circ}$ del Protocolo de Ouro Preto; es decir, la conducción política del proceso de integración.

En cuanto a sus efectos, (Art 9o del Protocolo de Ouro Preto) las decisiones "serán obligatorias para los Estados partes".

\section{B) Resoluciones:}

Las resoluciones son actos normativos emitidos por el Grupo Mercado Común para la ejecución de medidas tomadas para el desarrollo del Mercosur, de alcance obligatorio para los Estados miembros.
El grupo Mercado Común es el órgano ejecutivo del Mercosur (art. 10 Ouro Preto), y debe elaborar y proponer medidas para el desarrollo del Mercosur.-

Las resoluciones del Grupo Mercado Común serán obligatorias para los Estados partes (art. 15 del Protocolo de Ouro Preto).-

\section{C) Directivas:}

La Comisión de Comercio se pronunciará mediante directivas (art. 20 Ouro Preto).- Se trata de actos normativos de obligatoriedad para los Estados Partes, referidas al control del cumplimiento de los instrumentos de política comercial común acordados por los Estados para el funcionamiento de la Unión Aduanera (art. 16 Ouro Preto).

\section{D) Propuestas:}

El Protocolo se refiere a las propuestas de la Comisión de Comercio (art. 20) y del Foro Consultivo Económico Social (art. 29)- Las propuestas valen como consejo o expresión de la opinión del organismo que la efectúa.

\section{Colision de Normas Y Principios}

En sistemas normativos abiertos reviste fundamental importancia la solución de antinomias y colisiones de normas.- En el ámbito del Mercosur existen los Tratados, el derecho derivado, los derechos nacionales, y los tratados internacionales que han firmado los países integrantes, que proveen un cúmulo de normas y principios que, a la hora de su aplicación e 
interpretación, pueden suministrar soluciones contradictorias en diversa gradación.-

Por ello es necesario que tanto el interprete como quien aplica el derecho de la integración, aprenda a "moverse dentro del sistema", aprehendiendo algunos principios básicos para la resolución de conflictos.-

\section{Reglas de razonamiento aplicables}

Puede haber una colisión entre principios juridicos.- De hecho son muy frecuentes y mas aun en un sistema en vías de integración.-

En primer lugar corresponde distinguir entre conflicto de reglas y de principios.-

La colisión entre reglas produce el efecto de excluir una, porque el resultado de aplicar las dos es incompatible.- Se desenvuelve en el plano de la validez, al que se aplican los criterios tradicionales como precedencia temporal, jerarquía, etc.- En estos casos, la actividad de intérprete consiste en una opción: o una o la otra.

Cuando se trata de principios valores, no hay opción, sino ponderación ${ }^{30}$, y funcionan criterios argumentativos.- La aplicación de un principio no desplaza al otro, sino que lo precede en el caso concreto. - Se dice que los principios tienen diferente peso en el caso concreto, pero no son inválidos.- No se trata entonces de una antinomia en el sentido tradicional, sino de un campo de tensión.-

30. Cont. ALEXY, "Teoría..., cit)
El conflicto entre principios se soluciona mediante un juicio de ponderación de intereses opuestos.- Se trata de cuál de los intereses, abstractamente del mismo rango, tiene mayor peso en el caso concreto.- Esta concepción implica admitir que no hay principios absolutos.- Así lo dispone claramente la Convención Americana sobre derechos humanos al señalar en su artículo 32 que los derechos de cada uno están limitados por los derechos de los demás, y que hay deberes para con la familia, y la comunidad.-

Dar a cada uno lo suyo respetando los derechos ajenos exige dar a unos y sacar a otros, buscando un punto de equilibrio.No se trata de una optimización, sino de un punto de equilibrio óptimo, buscando la eficiencia.

La colisión no produce una exclusión, sino una restricción.

El juicio de ponderación expresa que la medida permitida de no satisfacción de un principio, depende del grado de importancia de satisfacción del otro.- La ponderación establece una relación, que puede ser expresada en curvas de indiferencia que representen la relación de sustitución de bienes.

Las curvas de indiferencia muestran esa relación: si disminuye la libertad de prensa porque se considera que debe ceder frente a la seguridad externa, es necesario verificar cada vez más aumentos de seguridad para compensar la disminución de libertad. - En el punto en que el cambio es indiferente se produce el equilibrio.
De este modo estamos en condiciones de disponer de una racionalidad mínima para examinar los puntos de equilibrio en la satisfacción de intereses y de normas, sin que por ello se llegue a extremos deformantes.-

Finalmente, hay que distinguir entre principios de distinto rango, principalmente entre los que tienen contenido patrimonial y extrapatrimonial. - La solución de la competencia mediante la búsqueda de un punto óptimo de eficiencia exige que se trate de normas de rango equivalente.-

Según nuestro juicio podrían sentarse las siguientes reglas:

- Concurrencia de bienes extrapatrimoniales y patrimoniales: habría preeminencia de los primeros.-

- Concurrencia de bienes patrimoniales la solución es cuantitativa. Ello exige un juicio de optimización en la asignación de recursos.-

- Concurrencia entre bienes extrapatrimoniales: en estos casos habrá un juicio de ponderación entre ellos.-

\section{La interpretación en favor de la integración:}

En el capitulo anterior hemos señalado que, de la normativa del Mercosur, puede desprenderse un principio de primacía atenuada, que a su vez permite sustentar una interpretación en favor de la integración.-

Esta afirmación tiene una gran relevancia. - Cuando un Estado firma un tratado internacional cede parte de su soberanía, y por ello su interpretación ha sido siempre restrictiva, puesto que lo que no ha sido expresamente cedido, permanece dentro de la soberanía estatal.

En los tratados de integración, el principio se invierte.- Los Estados manifiestan su deseo de avanzar en un proceso de integración, con los perfiles que ellos establecen.- Esta tendencia configura una ruta normativa que todo interprete debe seguir a la hora de decidir conflictos que involucren de alguna manera este proyecto.-

Este es uno de los valores que cabe adjudicar a los objetivos en las normas jurídicas: constituyen una guía para el interprete.

En el Tratado de Asunción y en muchos actos normativos posteriores, se ha puesto en claro que este es un objetivo normativamente asumido por los Estados.

\section{El problema de las barreras no arancelarias y los derechos \\ humanos}

El problema que se plantea bajo este tópico ocurre cuando un país tiene una legislación de protección del consumidor, $\mathrm{o}$ del medio ambiente, o similar que impide o restringe la entrada de empresas de otros países.

Así se configura una colisión entre el principio de la libertad de circulación y las denominadas barreras no arancelarias.

El Tratado de Asunción, en su articulo 1 dispone que el Mercado Común implica la "eliminación" de "restricciones no arancelarias".- En el anexo I del Tratado, referido al programa de liberación 
comercial, se define (art 2, b) como "restricción" a "cualquier medida de carácter administrativo, financiero, cambiario o de cualquier naturaleza, mediante el cual el Estado Parte impida o dificulte por decisión unilateral, el comercio reciproco.- No quedan comprendidos en dicho concepto las medidas adoptadas en virtud de las situaciones previstas en el articulo 50 del Tratado de Montevideo de 1980".-

El articulo 50 del Tratado de Montevideo de 1980 dice: "Ninguna disposición del presente tratado sera interpretada como impedimento para la adopción y el cumplimiento de medidas destinadas a la:

a)- protección de la moralidad publica,

b) - aplicación de leyes y reglamentos de seguridad,

c)- regulación de las importaciones de armas,

d)- protección de la vida y salud de las personas, los animales y los vegetales,

e)- importación o exportación de oro y plata metálicos

f)- protección del patrimonio nacional del valor artístico, histórico o arqueológico,

g) - exportación, utilización y consumo de materiales nucleares, productos radiactivos o cualquier otro material utilizable en el

desarrollo o aprovechamiento de la energía nuclear.

Esta claramente establecida una regla y sus excepciones.-

Para interpretar adecuadamente la misma, conviene tómar en cuenta la experiencia ajena.- En el ámbito de la Union Europea, el Tratado de Roma hace referencia a la supresión de restricciones "cuantitativas" y "medidas de efecto equivalente" (art 30).- En el articulo 36 establece que la eliminación de las restricciones no impide que se establezcan aquellas fundadas en el orden público, moralidad y seguridad publicas, protección de la salud y vida de las personas y animales, preservación de los vegetales, protección del patrimonio artístico, histórico o arqueológico nacional o protección de la propiedad industrial y comercial".-A renglón seguido, se indica que estas excepciones no pueden ser usadas como discriminación arbitraria o encubierta (art. 36).-

De ello se desprende que debe distinguirse adecuadamente aquellas disposiciones que protegen el orden público patrimoniales o extrapatrimoniales cuantitativos y cualitativos.- Este distingo es similar al que se ha establecido entre bienes monetizables o no en cuanto a su reparabilidad ${ }^{31}$.-

\section{El orden público como barrera no arancelaria referida a aspectos patrimoniales}

Puede suceder que un Estado considere que, no obstante existir una

31. Ampliamos en: "Las nuevas fronteras de la responsabilidad por daños", LL. 9.5.96.-

cuestión patrimonial, ella es de tal importancia que interesa al país y de esta manera necesite establecer barreras.

En la sentencia "Campus Oil" del 10/ 7/84 el Tribunal de Justicia de la Comunidad Europea, dijo que "... es cierto que el art. 36 persigue salvaguardar intereses de naturaleza no económica.- En efecto, un Estado miembro no esta autorizado para sustraerse a los efectos de las medidas previstas por el Tratado escudándose en las dificultades económicas ocasionadas por la eliminación de las trabas del comercio intracomunitario...".- El Tribunal pone de resalto la importancia crucial que el tiene para la existencia de un país por su fuente de energía y materia prima por excelencia, por lo que llega a considerar que el interés constituido para la salvaguardia de ese abastecimiento "rebasa" la naturaleza puramente económica y salvaguarda la existencia del Estado mismo, sus intereses fundamentales, el mantenimiento de sus instituciones, sus servicios públicos esenciales, la salud y la vida de sus habitantes."

El Tribunal de Justicia ha dicho que "la noción de orden público en el contexto comunitario y, en particular, como justificación de una excepción al principio fundamental de la libre circulación de los trabajadores, debe interpretarse restrictivamente de forma que su alcance no pueda determinarse unilateralmente por cada uno de los Estados miembros sin control de las instituciones de la Comunidad..." 32 abastecimiento de productos petrolíferos

El alcance del concepto de "orden público" no puede ser determinado unilateralmente por cada Estado. Aunque se aprecia de acuerdo con una "escala de valores nacional", esa valoración debe situarse en una prespectiva comunitaria. Es decir, que es necesario conciliar los intereses nacionales con los intereses comunitarios conforme lo expusiéramos al fundar el principio interpretativo en favor de la integración.-

\section{El orden público estatal como limite frente al derecho de la integración}

El orden público de un determinado país puede impedir la aplicación de una ley extranjera.- En Argentina el art. 14 del Código Civil veda la aplicación de la ley extranjera: 1) - "Cuando su aplicación se oponga al Derecho público o criminal de la República, a la religión del Estado, a la tolerancia de cultos o a la moral y buenas costumbres. 29) Cuando su aplicación fuere incompatible con el espíritu de la legislación de este Código. $3^{\circ}$ ) Cuando fueren de mero privilegio. $4^{\circ}$ ) Cuando las leyes de este Código en colisión con las leyes extranjeras fuesen mas favorables a la validez de los actos."

Entre los críticos a estas soluciones Goldschmidt entendió que el orden público como valla para la aplicación del derecho privado extranjero esta en relación inversa con el autentico espíritu del derecho internacional privado y constituye un termómetro de chauvinismo jurídico ${ }^{33}$.

32. Considerandos 33 a 35 de la Sentencia "Bouchereau" del 27/10/77.

33. GOLSCHMIT, Werner, "Derecho internacional privado", p. 317 y ss. 
Comprendemos la postura del maestro Golsdchmidt, en el sentido de la internacionalización y la convivencia entre las naciones.-

Sin embargo, este proceso de globalización tiene, o debiera tener, limites.La necesidad de un "Espacio" en un mundo globalizado es algo que ha sido advertido frecuentemente en la etnología y en la antropología contemporánea ${ }^{34}$; el hombré necesita un lugar, y lo diseña como modo de protección.- De allí el paradójico surgimiento de los nacionalismos, regionalismos, en el contexto de una tendencia global.-

No todo es materia de integración y ni siquiera de armonización.- Cada comunidad tiene su fisonomía propia, sus costumbres, cultura, proyectos de vida, que desea preservar frente a la integración.-

Es razonable que esto sea mantenido respetando la voluntad de los pueblos en este sentido, lo que justifica el mantenimiento del orden público interno en aspectos como los referidos.-

\section{La idea del ejercicio abusivo del orden público}

En estos cambios paradigmáticos que describimos, es interesante examinar la idea del uso abusivo del orden público.-
Si el objetivo es la integración y ello constituye una obligación jurídica de los Estados-Partes, es claro que el orden público estatal debe ser usado para la protección de valores que esa comunidad tiene y que no desea compartir.-

Estos son los fines que se le reconocen al orden público: protección de la moral, buenas costumbres, validez de los actos, espíritu de las leyes, todo lo cual puede ser resumido en una cultura propia, nacional o regional.- Este concepto se desnaturaliza cuando, con el pretexto de conservarlo se lesionan los derechos individuales, de un modo tal que no sólo se los restringe, sino que se los ahoga postulando la existencia de un orden público sin individuos.

De la misma manera, puede ser usado contra los fines que la ley tuvo en miras al reconocerlo, cuando se transforma en un instrumento para restringir indebidamente el acceso al mercado de una empresa que goza derecho de trato nacional.

El Tribunal de Justicia de la Comunidad Europea, en la causa "Rutili", estableció que para que el orden público pueda limitar la libre circulación debe ser usado frente a una "amenaza ral y suficientemente grave que afecta a un interés fundamental de la sociedad".

\title{
Colisão de Direitos Fundamentais e Realização de Direitos Fundamentais no Estado de Direito Democrático*
}

\author{
Pobext exlexy \\ Professor de La Universidad Christian - Albrecht de Kiel \\ Tradutor: Dr. Luís Afonso Heck, Prof. na UFRGS e ULBRA
}

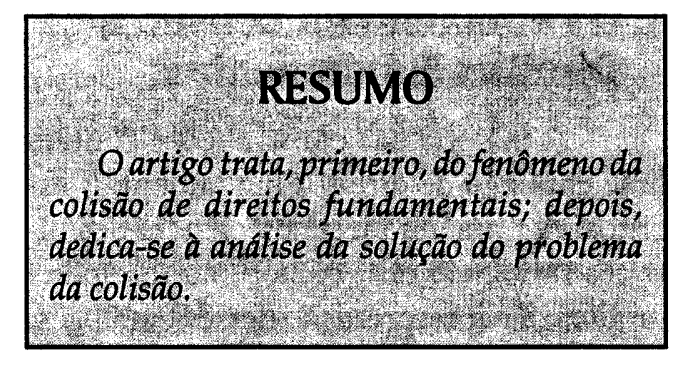

\section{SUMÁRIO}

I. O Fenômeno da Colisão de Direitos Fundamentais;

1. Colisões de direitos fundamentais em sentido estrito; a) Colisões de direitos fundamentais idênticos; $b$ ) Colisão de direitos fundamentais diferentes; 2 . Colisões de direitos fundamentais em sentido amplo;

II. A Solução do Problema da Colisão;

1. A força vinculativa dos direitos fundamentais; 2. Regras e princípios; a) $A$ distinção; b) As opções da teoria das regras; c) O caminho da teoria dos princípios; d) Vinculação e flexibilidade. direitos fundamentais são, por um lado, elementos essenciais da ordem jurídica nacional respectiva. Por outro, porém, eles indicam além do sistema nacional. Nessa passagem do nacional deixam-se distinguir dois aspectos: um substancial e um sistemático. Os direitos fundamentais rompem, por razões substanciais, o quadro nacional, porque eles, se que. rem satisfazer os requisitos que lhes podem ser postos, devem incluir os direitos do homem. Os direitos do homem têm, porém, independentemente de sua positivação, validez universal. ${ }^{1}$ Eles põem, por conseguinte, exigências a cada ordem jurídica. Uma contribuição importante para a sua concretização internacional forneceu e fornece a Declaração Universal dos Direitos do Homem, de 10 de dezembro de 1948. Os direitos do homem tornaram-se

Palestra proferida na sede da Escola Superior da Magistratura Federal (ESMAFE) no dia 07 de dezembro de 1998.

1. Comparar R. Alexy, Diskurstheorie und Menschenrechte, in: ders., Recht, Vernunft, Diskurs, Frankfurt a.M. 1995, S. 144 f. 